\title{
"Hérnias complexas" da parede abdominal
}

\section{Complex abdominal wall hernias}

\author{
tCBC-Go Renato Miranda de Melo
}

A hérnias ventrais, incluindo as epigástricas e umbilicais, as inguinais, as femorais e as incisionais se revestem de grande importância médica, seja por sua frequência mais elevada ou pelas repercussões clínicas mais graves que podem acarretar.

Entretanto, permanece imprecisa a classificação da hérnia incisional, que mesmo passível de ocorrer em qualquer região do abdome, onde haja uma cicatriz, está inserida entre as ventrais, cuja localização é especificamente anterolateral, segundo os Descritores em Ciências da Saúde (DeCS/BIREME) e a Classificação Estatística Internacional de Doenças e Problemas Relacionados à Saúde, em sua $10^{\text {a. }}$ revisão (CID-10). Essas mesmas convenções internacionais também não diferenciam as hérnias primárias das recidivadas nem levam em consideração seu tamanho ou volume, seja do anel ou do conteúdo herniado, que podem variar amplamente. Vale ressaltar ainda que, por definição, toda hérnia recidivada é também uma hérnia incisional, e como tal deverá ser considerada.

Um dos desdobramentos dessa incerteza é que o Sistema Único de Saúde (SUS), e muitos dos planos e seguros privados, não reconhecem que hérnias primárias (epigástricas, umbilicais, inguinais e femorais/crurais) sejam passíveis de grande crescimento, ainda que mais raramente. Assim, reservam para o seu reparo apenas as próteses (telas) de tamanho pequeno, como se todas elas tivessem anel herniário e conteúdo pequenos sempre. E seguem o mesmo critério para o tratamento do que denominam "hérnias recidivantes". Quanto às incisionais, prevêem a utilização de telas médias, com base na mesma premissa, não raras vezes, exigindo justificativa para as próteses grandes e sobretudo para as especiais.

No tocante às hérnias epigástricas e umbilicais, grande parte das vezes são defeitos pequenos, que dão passagem apenas à gordura pré-peritonial, e seu tratamento é obtido por sutura simples do anel, recompondo o estrato musculoaponeurótico, após a exérese ou a redução do conteúdo herniado. O mesmo não se aplica àquelas que atingiram volumes maiores, como ocorre na maioria das hérnias incisionais e também em algumas inguinais primárias, pois exigem procedimentos mais elaborados e onerosos (grande porte), incluindo a utilização de telas especiais e de tamanho grande, além de demandarem maior tempo no preparo e na recuperação desses pacientes.

A despeito de o volume do conteúdo herniado não guardar relação com o tamanho do anel, algumas podem adquirir grandes proporções, provocando a perda de domicílio das vísceras e estruturas abdominais, em que parte considerável desses elementos se aloja no saco herniário. Este pode atingir $20 \%$ ou mais do volume abdominal, constituindo uma "segunda cavidade", o que provoca alterações graves na dinâmica ventilatória, na postura corporal, no retorno venoso e no linfático, na motilidade intestinal e na perfusão esplâncnica, especialmente a renal, e também da pele, como as dermatites, as úlceras e o abdome em avental. Da mesma forma, a redução pura e simples do conteúdo herniado, sem o devido preparo do paciente (e da cavidade abdominal primitiva), pode não só inviabilizar a redução desse conteúdo, mas também gerar complicações graves, decorrentes do aumento súbito da pressão intra-abdominal (PIA), como a síndrome de compartimento abdominal, que pode ser letal.

Algumas comorbidades, como hipertensão, diabetes e obesidade, que são comuns nesses casos, aumentam a frequência de complicações, dificultando o manejo clínico desses pacientes e, muitas vezes, exigem que o seu tratamento seja realizado em Unidade de Terapia Intensiva. Além disso, a necessidade quase imperativa do uso de telas grandes e especiais, para reduzir a possibilidade de recidiva, elevam os custos assistenciais, onerando ainda mais as fontes pagadoras.

Esses e outros desafios fazem com que os pacientes, nessas condições, sequer sejam admitidos na maioria dos serviços cirúrgicos, sobretudo aqueles que atendem ao SUS. É um risco proibitivo para os primeiros e um obstáculo às vezes intransponível para os últimos. Isso acaba por forçar o referenciamento desse contingente para hospitais públicos e universitários, gerando longas filas de espera e o afastamento desnecessário de indivíduos, muitas em idade produtiva, seja do mercado de trabalho ou do convívio social. A principal razão que leva esses pacientes a procurar atendimento, com todas as mazelas da exclusão a que estão subjugados, é a intenção de melhorar a qualidade de vida, entendida de maneira global.

Mas padecer de uma hérnia complexa não é prerrogativa das classes menos favorecidas.

Na verdade, as hérnias reúnem muitas afecções sob uma única denominação, mas trata-se de um grupo bastante heterogêneo. A etiologia é multifatorial, as repercussões são variadas, assim como as complicações também podem ser múltiplas. Portanto, o tratamento adequado deverá ser particularizado, multimodal e, por vezes, multiprofissional. O objetivo é devolver o conteúdo herniado à cavidade abdominal, corrigir o defeito e recuperar a função da parede, com o mínimo de complicações e de sequelas. 
Não há procedimento considerado padrão-ouro para corrigi-las. E mais, nas dobras e no domo do saco herniário, a pele redundante pode apresentar-se macerada ou mesmo ulcerada e, nos casos de abdome em avental, ela deverá ser ressecada (dermolipectomia), para facilitar a abordagem cirúrgica e a higienização, além de ajudar a reerguer a autoestima dos pacientes.

Por tudo isso, os portadores de hérnias volumosas, associadas a alterações locais e sistêmicas graves, exigem atenção e cuidados redobrados. Não raras vezes, impõem-se medidas preliminares de expansão da cavidade abdominal, mediante insuflação de ar ambiente ou de gás carbônico (pneumoperitônio progressivo pré-operatório) e/ ou bloqueio farmacológico da musculatura lateral do abdome, com toxina botulínica do tipo A, na tentativa de favorecer a redução do conteúdo herniado e de prevenir simultaneamente, a síndrome compartimental. O fortalecimento diafragmático e a melhora da expansibilidade pulmonar, pela fisioterapia respiratória e motora, são fundamentais para que a correção desses defeitos maiores não prejudique ainda mais a função pulmonar, já comprometida pela própria hérnia. Da mesma forma, deve-se compensar as deficiências nutricionais, por meio de reposição específica, seja por dieta oral, enteral ou parenteral. Abordagens simplistas, imediatistas ou intempestivas estão sujeitas ao fracasso, que pode variar desde uma recidiva a mais até o óbito, dado o alto grau de complexidade inerente a esses casos.

Se não bastassem tais desafios, as planilhas de custo dos planos de saúde, públicos ou privados, não diferenciam o tratamento de quadros mais complexos daqueles mais simples. Todos são nivelados em patamar único e mínimo, para fins de remuneração. Enquanto o trabalho médico e os gastos hospitalares, sobretudo com o pessoal de apoio (enfermeiros, fisioterapeutas e nutricionistas), são subestimados, os materiais utilizados para esse fim (telas e grampeadores, por exemplo) são sobrevalorizados, quan- do não sobretaxados, o que faz seu custo final subir exponencialmente. De forma paradoxal, paga-se bem mais por um dispositivo industrializado, fabricado em série, do que pelo trabalho particularizado, caso a caso, para implantá-lo com segurança em um organismo já adoecido. É útil lembrar que a responsabilidade do médico, assim como a do fabricante desses materiais, não se encerra ao final do procedimento cirúrgico, mas se prolonga por vários anos nos pacientes que receberam qualquer tipo de prótese.

Atualmente, tanto no âmbito do SUS como no da Agência Nacional de Saúde Suplementar (ANS), não há procedimento específico que contemple o tratamento dessas lesões mais complexas. Ao corrigir tais defeitos, muitos deles gigantescos, o médico despende várias horas de trabalho, em procedimentos laboriosos e de execução desafiadora, até para aqueles com maior experiência clínica, e por remuneração muito aquém do justo.

Também não há consenso sobre o que seja uma hérnia complexa, tampouco do seu manejo ideal, e menos ainda do valor pela contraprestação dos serviços, ao contrário de outras afecções, não menos graves da parede abdominal, como a onfalocele e a gastrosquise, que figuram entre as malformações do sistema osteomuscular.

É premente que tais questões sejam reexaminadas, a fim de inserir as "hérnias complexas da parede abdominal", neste rol, com base na elevada gravidade desses casos, e para que o seu tratamento seja realizado em serviços com capacidade instalada adequada (recursos humanos e tecnológicos) e também para que seja valorizado de forma proporcional à alta complexidade dos procedimentos.

Assim como fez a Cirurgia Bariátrica e Metabóli$\mathrm{ca}$, qualquer proposta deverá partir da definição do que se entenda por "hérnia complexa" e do credenciamento de serviços preparados para tratá-la adequadamente. 